\title{
Artificial Bee Colony Algorithm Based Approach for Power System Oscillation Damping with PSS and STATCOM
}

\author{
Saeid Fazeli-Nejad ${ }^{1}$, Ghazanfar Shahgholian ${ }^{2 *}$, Majid Moazzami ${ }^{3}$ \\ ${ }^{1}$ Smart Microgrid Research Center, Najafabad Branch, Islamic Azad University, Najafabad, Iran. \\ ${ }^{2}$ Department of Electrical Engineering, Najafabad Branch, Islamic Azad University, Najafabad, \\ Iran.
}

*Corresponding Author:GhazanfarShahgholian, Department of Electrical Engineering, Najafabad Branch, Islamic Azad University, Najafabad, Iran.

\begin{abstract}
This paper develops a design procedure for simultaneous coordinated designing of the static synchronous compensator controller parameters (STATCOM) and power system stabilizer (PSS) in multimachine power system. The artificial bee colony $(A B C)$ algorithm is employed to search for optimal controllers parameters. ABC algorithm is a collective intelligence based on optimization algorithm inspired by the feeding behavior of bees in finding food. Rapid convergence and high precision are the capabilities of this algorithm which in this study to demonstrate its effectiveness and robustness, a two zone - four machines system is used and analyzed through non-linear simulation of time-domain and the results are compared with particle swarm optimization (PSO) algorithm. The optimization after a large turbulence shows that the coordinated design of the STATCOM and PSS controllers' parameters using the ABC algorithm considerably improves the system stability together with rapid damping of the system fluctuations as compared to the state without optimization. On the other hand, the optimization results using the ABC algorithm shows the superiority of this method over the PSO algorithm.
\end{abstract}

Keywords: ABC algorithm, combinatorial optimization, PSO, FACTS.

\section{INTRODUCTION}

Studying different power blackouts around the world reveals that the main causes in such power failures lie in the voltage collapse and consecutive overloads due to recurrent tripping of relays and circuit breakers [1,2]. For this reason, using control devices and power system stabilizer (PSS) can grossly improve the static stability, dynamic stability, transient stability and the network voltage and in the meantime, the overloaded lines and voltage collapse can be prevented through maintaining balance between the power production and demand $[3,4]$. Reactive power compensation is a major issue in power systems and flexible ac transmission systems (FACTS) play an important role in controlling the power system's reactive power and voltage fluctuations and the system stability as well $[5,6]$.

A static synchronous compensator (STATCOM) is capable of injecting independently controllable reactive power into the system $[7,8]$.It provide continuously variable reactive power at its point of connection with the grid. STATCOM can used to maintain the magnitude of the bus voltage constant $[9,10]$. Power system stabilizer (PSS) and FACTS controllers are acceptable solutions for voltage and oscillatory instability problems, since these controllers increase loading margins and provide additional system damping [11,12]. PSS is widely used in existing power systems in order to damp out power system oscillations $[13,14]$. When a STATCOM is present in a power system to support the bus voltage, a supplementary damping controller could be designed to modulate the STATCOM bus voltage in order to improve damping of system oscillations $[15,16]$. But, the interaction among PSS and STATCOM-based controller may enhance or degrade the damping of certain modes of rotor's oscillating modes. To improve overall system performance, many researches were made on the coordination between PSS and FACTS power oscillation damping controllers [17,18]. Although the local control signals are easy to get, they are not as highly controllable and observable as wide area signals for the inter-area oscillation modes. Due to restriction of local measurements, these controllers based on local signals tend to be difficult to offer satisfactory performance under various system operating conditions. With the rapid advancement in wide area measurement systems technology, fast communication networks and powerful information technology, the widely dispersed signals of power systems 
can be centralized, processed and distributed even in real time, which makes the wide area signal a good alternative for control input [19].

A number of conventional techniques have been reported in the literature pertaining to design problems of conventional PSS: the eigenvalue assignment, mathematical programming, gradient procedure for optimization and also the modern control theory. Unfortunately, the conventional techniques are time consuming as they are iterative and require heavy computation burden and slow convergence. In addition, the search process is susceptible to be trapped in local minima and the solution obtained may not be optimal [20,21].

In recent decades given the inherent problems with the optimization methods and inapplicability of such methods to a special category of the functions, the goal of using optimization and heuristic methods was extensively welcomed. Broad applicability, ease of use and the capability to reach the answers close to the optimized values are among the reasons why the researchers are focusing their attention to these methods [22,23].

Many artificial intelligence optimization methods for regulation and coordinated design of the multistabilizer have been implemented through using artificial neural networks. Although the collective intelligence optimization methods were successfully used for solving the optimization problems but the current studies have identified their functional deficiencies. Intelligent algorithms such as genetic algorithm (GA) are capable of solving any optimization problems describable using chromosomal encryption and can be used for solving multi-dimensional, discrete and non-parametric problems; however they are sometimes unable to find general extreme and stall at local extreme level [24,25]. The PSO algorithm, although very simple and fast, still has a drawback in terms of the answer accuracy relative to the newer algorithms like ABC algorithm [26,27]. Also there is the local search based simulated annealing algorithm for which designing suitable local searching methods considering the conditions and limitations of the simulated problems is of particular importance $[28,29]$. This decline of qualification rate is increased specially with more complex target functions such as those in which the optimized parameters have intense dependency to each other and in functions with optimized parameters. Furthermore, the decrease of search ability as the result of premature convergence increases trapping possibility in local optimized points [30].

In order to increase the optimization process accuracy for coordination of STATCOM and PSS the $\mathrm{ABC}$ algorithm can be used which features good accuracy and convergence speed. Optimal location and controller design of STATCOM for power system stability improvement using PSO has been analyzed [31]. Also the coordinated design of PSS and STATCOM controller parameters using ABC algorithm has been performed and the results of the two above algorithms have been applied in regulating the PSS and STATCOM controller parameters in order to damping the fluctuations in a two-regional four-machines system and the findings have been compared with the results of the state without using the algorithm in adjustment of the parameters.

\section{Power System Oscillations DAMPING}

PSS and FACTS devices can help the damping of power system oscillations [32,33]. PSS provides an additional input signal to generate supplementary control signals for the excitation control system in order to damp slow mode oscillations of the power system [34,35]. The basic function of PSS is producing a component of electrical torque in phase with rotor speed deviations to increase the system positive damping. The conventional lead-lag PSS (CPSS) is show in Fig. (1-a) [36,37], where $T_{Q}$ is the washout time constant and $\mathrm{K}_{\mathrm{Q}}$ is the PSS pure gain. The selection of the $\mathrm{T}_{\mathrm{Q}}$ value depends upon the type of mode under study [38,39]. The time constants $\mathrm{T}_{1 \mathrm{P}}, \mathrm{T}_{2 \mathrm{P}}$ and $\mathrm{K}_{\mathrm{P}}$ are calculated using PSO and $\mathrm{ABC}$ algorithms.

A static synchronous compensator (STATCOM) is one of the FACTS devices that can provide effective means for controlling reactive power flow and improving the voltage regulation of a power system [40]. A STATCOM is capable of injecting independently controllable reactive power into the system. It provides continuously a variable reactive power at its linking point to the grid [41]. In this study a two-step lead-lag phase compensator block accompanied by a general gain and washout high pass filter together with an output limiter has been used in the STATCOM controller structure as show in Fig. (1-b), so that the two-step phase compensation block compensates for the appropriate leading-lagging power factors between the signal input-output. $\mathrm{K}_{\mathrm{C}}$ and times constant of lead-lag network $\mathrm{T}_{1 \mathrm{~S}}, \mathrm{~T}_{2 \mathrm{~S}}, \mathrm{~T}_{3 \mathrm{~S}}$ and $\mathrm{T}_{4 \mathrm{~S}}$ can be calculated using $\mathrm{ABC}$ algorithm. 


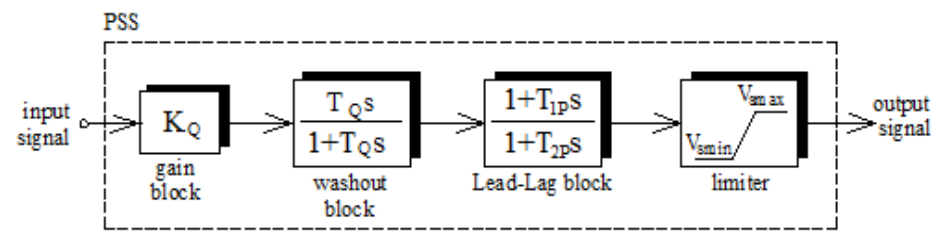

(a) Structure of the PSS

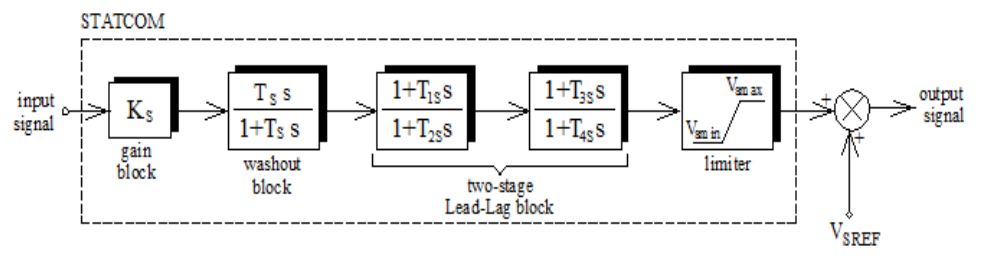

(b) Structure of the STATCOM-based controller

Fig1. Power System oscillation damping

\section{ARTificial BeE COLONY Algorithm}

The $\mathrm{ABC}$ algorithm has been inspired by the Bee behavior in the nature. Similar to the natural bee colony, this algorithm is constituted from three 'employed', 'onlookers' and 'scouts' bee groups. Initially a collection of food sources are randomly selected and the employed bees will go and calculate the amount of nectar of the selected source. Afterwards thy return to the colony and share their information with other bees (onlookers). In the second step, after sharing the information, each employed bee returns to the source it has seen before and it may also select a new source on the neighborhood of the previous source based on the visual information it has gathered from the place; that is the bee considering the color and type of the flower decides to go to the previous source or choose a new one. In the third step the onlookers will prefer a food source range based on the information they have collected from the employed bees in the dancing place. After reaching the place they may choose a new source around using the visual information they acquire from the area. When a source is cleared or it must be abandoned, a new source randomly found by the scouts will be replaced. The above cycle will be repeated until fulfillment of all the needs [42]. As was said before, each of the employed bees or the onlookers may make changes of the location of the food source (the solution) in their memory and calculate its qualification rate in relation to the other sources; in case the qualification rate of a source seems higher than the previous source in the bee's judgment, it selects the new solution and the old solution will be ignored and otherwise, the previous solution shall remain valid. These changes are obtained through the following relationship [43]:

In first, initialization of the population:

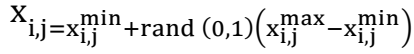

$$
\begin{aligned}
& \mathrm{i}=\{1,2, \ldots, \mathrm{SN}\}, \quad \mathrm{J}=\{1,2, \ldots, \mathrm{N}\}
\end{aligned}
$$

$\mathrm{x}_{\mathrm{i}, \mathrm{j}}^{\min }$ is the lower limit and $\mathrm{x}_{\mathrm{i}, \mathrm{j}}^{\max }$ is the upper limit of each optimization parameter. In the second step of the algorithm, initialization of Bee phase:

$$
\mathrm{V}_{\mathrm{i}, \mathrm{j}}=\mathrm{X}_{\mathrm{i}, \mathrm{j}}+\varphi_{\mathrm{i}, \mathrm{j}} \cdot\left(\mathrm{X}_{\mathrm{i}, \mathrm{j}}-\mathrm{X}_{\mathrm{k}, \mathrm{j}}\right)
$$

$\mathrm{i} \neq \mathrm{k}, \mathrm{k} \in\{1,2, \ldots, \mathrm{BN}\}, \mathrm{J} \in\{1,2, \ldots, \mathrm{D}\}$

where $\mathrm{X}_{\mathrm{i}, \mathrm{j}}$ is the previous location, $\mathrm{i}$ is the current bee, $\mathrm{k}$ is the neighboring bee and $\mathrm{D}$ is the number of optimization parameters. $\varphi_{\mathrm{ij}}$ is a random number between $[-1,1]$. This variable controls the location production of the neighborhood food resources around $\mathrm{X}_{\mathrm{ij}}$.In this relationship, BN represents the number of employed bees and the variable $\mathrm{k}$ is selected randomly, different from the variablei Themorethedifferencebetween $X_{\mathrm{ij}}$. and $\mathrm{X}_{\mathrm{kj}}$ is decreased, the lower the deviation from the location $\mathrm{X}_{\mathrm{ij}}$ will be. In fact, in this relationship we try to choose one dimension from among different dimensions of one of the locations and move in that direction or opposite to that direction (like PSO algorithm), depending on the value of $\varphi$, with the difference that-through we random selection try to create diversity and avoid from staying in the optimal local. After finishing of the searching process, the onlookers will evaluate the information of each one of the employed bees and using a probability of the source nectar quality, will choose one of the food sources. This probability is obtained from the following relationship[44]: 


$$
P_{i}=\frac{f i t_{i}}{\sum_{n=1}^{S N} f i t_{n}}
$$

In this relationship thefit is the qualification rate of the food source corresponding to the $i_{\text {th }}$ bee and $\mathrm{SN}$ is the number of existing solutions. In the case when a source comes to an end or its quality is inappropriate, the employed bee will leave that and will become a scout. In modelling this behavior, if the qualification rate of a point is not improved after several repetition (of which is shown by the parameter 'limit'), this means that we are at an optimal local. Accordingly, the relevant point is removed and a new point is randomly produced $[45,46]$.

For obtaining the optimization parameters using the $\mathrm{ABC}$ algorithm the following steps must be taken:

1- The system data and $\mathrm{ABC}$ algorithm parameters like the colony bees (number of employed bees + onlooker bees) (Np), the limit value and the number of cycles (max cycles) are specified.

2- Producing the initial conditions for each employed bee (determining the initial conditions for optimization parameters' values)

Each individual bee from the population is randomly given a value observing the limitations mentioned in equations (10) and (11).

3- The attraction of the initial random values is determined by replacement in the Formula (7).

4- It should be noted that due to considering the optimization parameters in Simulink, optimization must be implemented so that the system variables for determining the target functions are specified.

5- In this step the searching process must be performed in three methods to improve the answer. (The employed bees: local searching, onlooker bees: choosing selected answers for the local search, scouts bee: surveying new random answers).

6- The algorithm's termination term is reaching to the maximum repetition value (max cycle) and in case of not fulfilling of all steps, the steps 4 onwards are repeated.

The ABC algorithm flowchart used in coordinated designing of PSS and facts controller has been represented in Fig. 2.

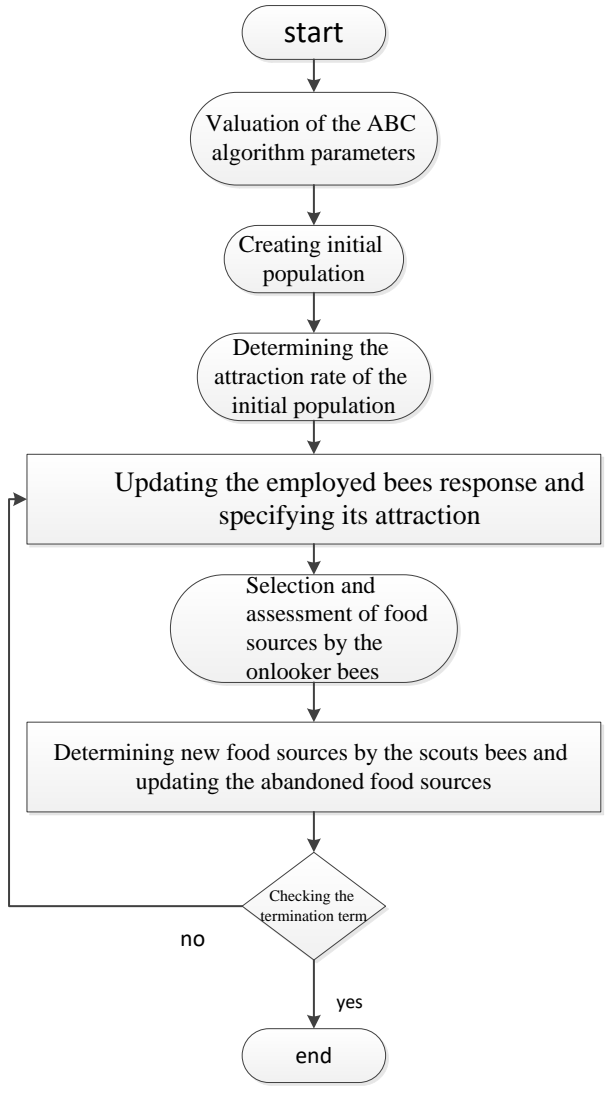

Fig2.Flowchart ABC algorithm 


\section{ApPlication Procedure OF Honey Algorithm on POWER System}

The two area-four machine system includes two symmetrical areas as shown in the Fig. 3. This system has been engineered particularly $[47,48]$ for investigating the low electromechanical frequency fluctuations in large interconnected power systems. This system can simulate the actual behavior with a reasonable accuracy.

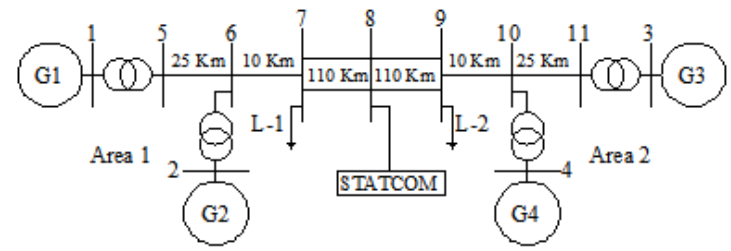

Fig3. Two-area four-machine power system with STATCOM

In the STATCOM controller, the washout time constant will be equal to 10s and other time constants shall be as follows $T_{25}=T_{45}=0.3 \mathrm{~s}$. The Ks controller gain and the $\mathrm{T}_{1 \mathrm{~s}}, \mathrm{~T}_{3 \mathrm{~s}}$ controller time constants are determined by the algorithm for optimization. The PSS controller structure the washout is equal to $3 \mathrm{~s}$. The $K_{P}$ stabilizer gain and the parameters $T_{1 S}$ and $T_{2 S}$ are determined by the intelligent algorithms for optimization. In this study the internal absolute error of the speed deviation in simulation time span has been used as the target function and is described as follows [30]:

$j=\int_{t=0}^{t=t_{\text {sim }}}(|\Delta \omega|) t d t$

To calculate this function, the non-linear model of the system in time domain of the simulation time span is executed. The objective is that the target function for the improvement of system response based on the subsidence time and the overshoot rate is minimized. The aim of this study is minimization of the $\mathbf{J}$ proposed cost function. Accordingly the optimization problem is defined as follows [30]:

$$
j=\int_{t=0}^{t=t_{\text {sim }}}\left(\sum \Delta \omega_{L}+\sum \Delta \omega_{I}\right) t d t
$$

where $\Delta \omega_{\mathrm{L}}$ and $\Delta \omega_{\mathrm{I}}$ are the speed deviations of local and inter-area modes of oscillations, respectively, and $t_{\text {sim }}$ is the time range of the simulation. Limitations of the problem include the STATCOM and PSS based controller parameters. The STATCOM limitations are:

$$
\left\{\begin{array}{l}
K_{S}^{\min } \leq K_{S} \leq K_{S}^{\max } \\
T_{1 S}^{\min } \leq T_{1 S} \leq T_{1 S}^{\max } \\
T_{3 S}^{\min } \leq T_{3 S} \leq T_{3 S}^{\max }
\end{array}\right.
$$

and the PSS limitations are equal to:

$$
\left\{\begin{array}{l}
K_{P N}^{\min } \leq K_{P N} \leq K_{P N}^{\max } \\
T_{1 N}^{\min } \leq T_{1 N} \leq T_{1 N}^{\max } \\
T_{2 N}^{\min } \leq T_{2 N} \leq T_{2 N}^{\max }
\end{array}, N=1, \ldots, 4\right.
$$

The introduced method consists of using the $\mathrm{ABC}$ algorithm for solving the optimization problem to obtain the PSS and STATCOM parameters. Also, all the relevant parameters are given in Appendix.

\section{SimUlation RESUltS}

In this section the simulation results of a large oscillation occurred due to short-circuit in $1.0 \mathrm{~s}$ to $2.0 \mathrm{~s}$ time span have been presented. By Coordinated designing of PSS and STATCOM controller parameters using $\mathrm{ABC}$ algorithm and comparing the results with PSO algorithm, the unknown values as shown in Table 1 are obtained. In order to obtain the simulation results using the PSO algorithm the values presented in Table 2 are used.

The unknown optimization parameters shown in Table 1 have been presented in Table 3 after application of PSO algorithm. To obtain the simulation results using ABC algorithm, the values shown in Table 4 are used. 
Artificial Bee Colony Algorithm Based Approach for Power System Oscillation Damping with PSS and STATCOM

TABLE1.UNKNOWN PARAMETERS OF OPTIMIZATION

\begin{tabular}{|c|c|c|c|c|c|}
\hline $\begin{array}{c}\text { Controller } \\
\text { parameters }\end{array}$ & STATCOM & PSS1 & PSS2 & PSS3 & PSS4 \\
\hline Gain & $\mathrm{K}_{\mathrm{S}}$ & $\mathrm{K}_{\mathrm{Q} 1}$ & $\mathrm{~K}_{\mathrm{Q} 2}$ & $\mathrm{~K}_{\mathrm{Q} 3}$ & $\mathrm{~K}_{\mathrm{Q} 4}$ \\
\hline $\begin{array}{c}\text { Time } \\
\text { Constant }\end{array}$ & $\mathrm{T}_{1 \mathrm{~S}}$ & $\mathrm{~T}_{1 \mathrm{P}}$ & $\mathrm{T}_{1 \mathrm{P}}$ & $\mathrm{T}_{1 \mathrm{P}}$ & $\mathrm{T}_{1 \mathrm{P}}$ \\
\cline { 2 - 6 } & $\mathrm{T}_{3 \mathrm{~S}}$ & $\mathrm{~T}_{2 \mathrm{P}}$ & $\mathrm{T}_{2 \mathrm{P}}$ & $\mathrm{T}_{2 \mathrm{P}}$ & $\mathrm{T}_{2 \mathrm{P}}$ \\
\hline
\end{tabular}

TABLE2.THE VALUES USED IN THE ALGORITHM PSO

\begin{tabular}{|c|c|}
\hline Parameter & Value \\
\hline MaxCycle & 100 \\
\hline Limit & 40 \\
\hline Npop & 20 \\
\hline Nvar & 15 \\
\hline $\mathrm{C}_{1}, \mathrm{C}_{2}$ & 1,1 \\
\hline
\end{tabular}

TABLE3.THE OPTIMIZED PARAMETERS $T_{I S}, T_{3 S}$ IN STATCOM CONTROLLER AND $T_{I S}, T_{3 S}$ IN PSS CONTROLLER USING THE PSO ALGORITHM

\begin{tabular}{|c|c|c|c|c|c|}
\hline $\begin{array}{c}\text { Controller } \\
\text { parameters }\end{array}$ & STATCOM & PSS-1 & PSS-2 & PSS-3 & PSS-4 \\
\hline Gain & 75.4313 & 109.985 & 125.4235 & 113.8497 & 75.9578 \\
\hline \multirow{2}{*}{ Time constant } & 0.5241 & 0.2786 & 0.3604 & 0.0279 & 0.3689 \\
\cline { 2 - 6 } & 0.5764 & 1.5289 & 0.8156 & 0.6822 & 0.7616 \\
\hline
\end{tabular}

TABLE4. THE VALUES USED IN THE ALGORITHM ABC

\begin{tabular}{|c|c|}
\hline Parameters & Value \\
\hline Max Cycle & 100 \\
\hline Np & 50 \\
\hline Limit & 40 \\
\hline Food Number & 25 \\
\hline D & 15 \\
\hline
\end{tabular}

To obtain the simulation results using the $\mathrm{ABC}$ algorithm, a two-area four-machine system and the Table 5 values gained from the algorithm ABC are used. During the simulation, the response of components like the generators' speed, rotor angle, terminal voltage and transmission power of the generators, etc. after short-circuit oscillation is obtained and illustrated.

TABLE5.THE OPTIMIZED PARAMETERS OF TIS AND T3S IN STACOM CONTROLLER AND THE PARAMETERS TIS AND T2S IN PSS CONTROLLER USING THE ABC ALGORITHM

\begin{tabular}{|c|c|c|c|c|c|}
\hline $\begin{array}{c}\text { Controller } \\
\text { parameters }\end{array}$ & STATCOM & PSS-1 & PSS-2 & PSS-3 & PSS-4 \\
\hline Gain & 24.0979 & 118.3654 & 123.7898 & 128.7844 & 81 \\
\hline \multirow{2}{*}{ Time constant } & 0.8386 & 0.303 & 0.3697 & 0.0238 & 0.3633 \\
\cline { 2 - 6 } & 0.358 & 1.54 & 0.8185 & 0.6814 & 0.7659 \\
\hline
\end{tabular}

The voltage change and the reactive power of bus connected to the STATCOM bus are shown in Fig. 4. The V-B1 and V-B2 voltage changes or $L_{1}, L_{2}$ loads shown in the power system after the 3-phase short-circuit oscillation have been represented in Fig. (5-a). The system's active power transmitted from the bus B1 to B2 illustrated in power system after 3-phase short-circuit oscillation has been represented in Fig. (5-b).

Changes of the variables like the voltage angle, speed, power and terminal voltage of the generators 1 to 4 after 3-phase short-circuit oscillation have been presented. In the Fig. (6-a) the voltage angle changes of the generators 1,3 and 4 relative to the generator 2 connected to the bus slack with zero angel have been measured and illustrated. Fig. (6-b) shows the speed changes of the generators 1 to 4 as per unit after the 3-phase short-circuit oscillation. This figure shows that the generators' speed fluctuations are damped quickly after the oscillation. Fig. (6-c), showing the per unit active power in generators 1 to 4 , describes how such fluctuations become zero after the short-circuit oscillation. Fig. 7 shows the terminal voltages of the generators 1 to 4 and Variation of STATCOM reference voltage signal under small disturbance, respectively. 


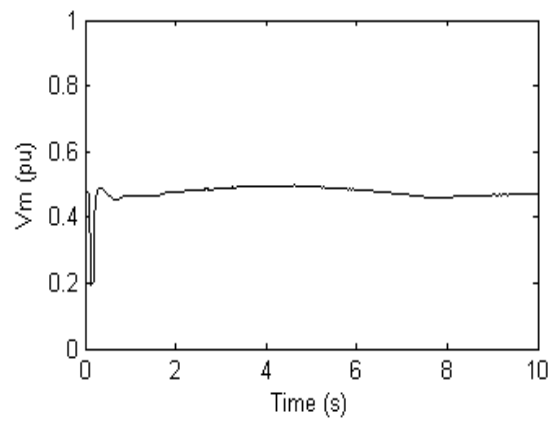

(a) Voltage changes

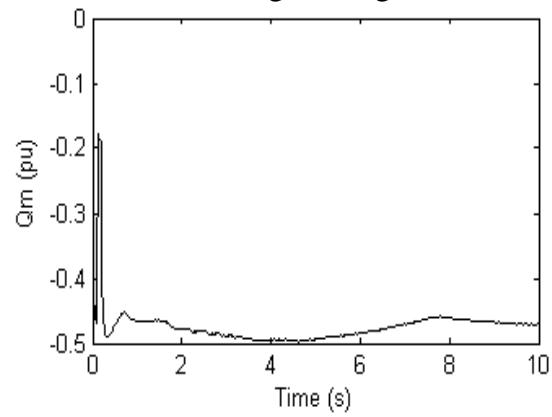

(b) Reactive power changes

Fig4. Changes in the voltage and reactive power in the bus connected to STATCOM

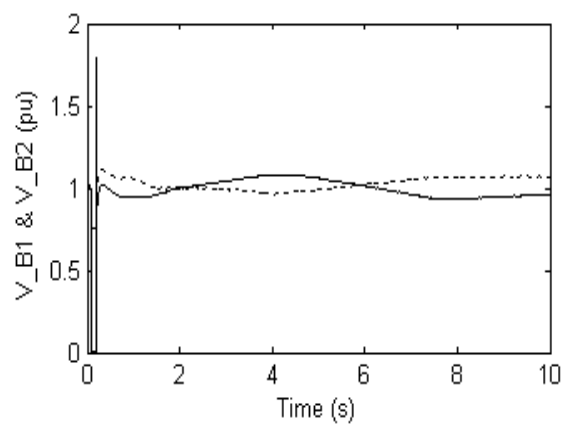

(a) Voltage changes in the buses [B1 (dotted) and B2 (solid)]

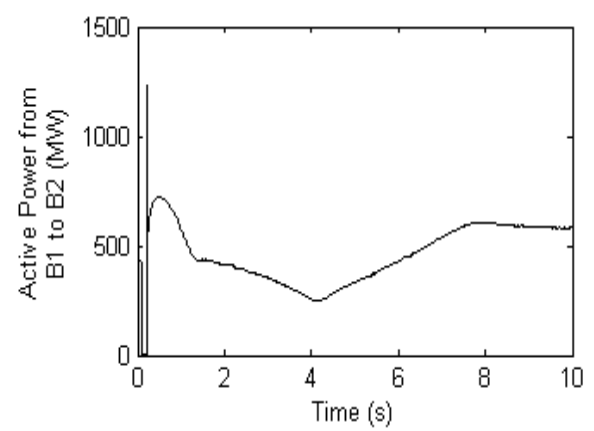

(b) Active power changes transmitted from the bus B1 to the bus B2

Fig5. Voltage changes and active power transmitted after the 3-phase short-circuit oscillation

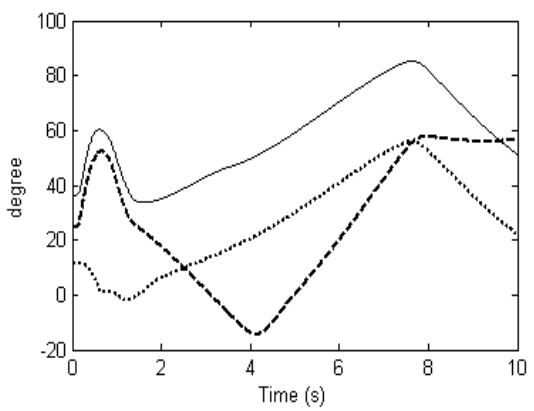

(a) Voltage angle changes of the generators 1 (solid), 3 (dot) and 4 (dash) relative to the generator 2

International Journal of Research Studies in Electrical and Electronics Engineering (IJRSEEE) Page | 33 


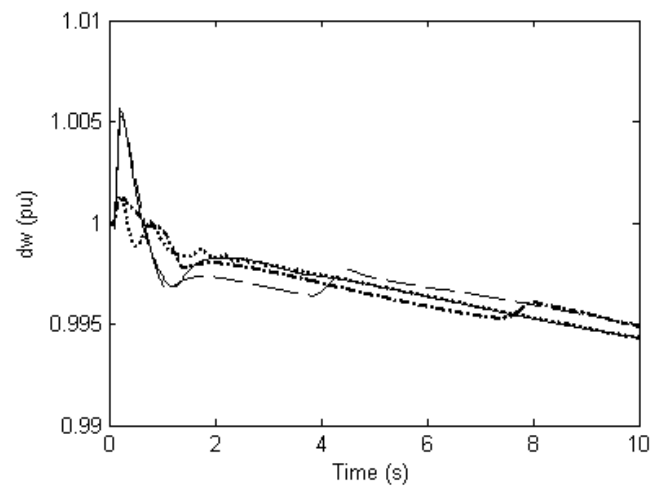

(b) Speed changes of the generators 1 (dash), 2 (solid), 3 (dash-dot) and 4 (dot)

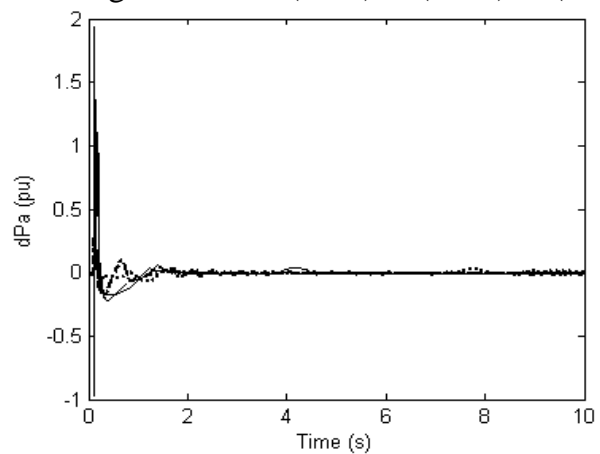

(c) Power changes of the generators 1 (dash), 2 (solid), 3 (dash-dot) and 4 (dot)

Fig6. Changes of the variables of the generators 1 to 4 after 3-phase short-circuit oscillation

These figures show the system components' response after the 3-phase short-circuit oscillation. In order to indicate the efficiency of the $\mathrm{ABC}$ algorithm, the results of this algorithm have been compared with the findings from application of the PSO algorithm as well as the results from the state without optimization of the system parameters. At first the convergence graph of the function $\mathbf{J}$ relative to the number of repetition has been represented in Fig. 8. The red and blue lines represent the convergence graph of the target function $\mathrm{J}$ relative to the number of repetitions in algorithms PSO and $\mathrm{ABC}$ respectively.

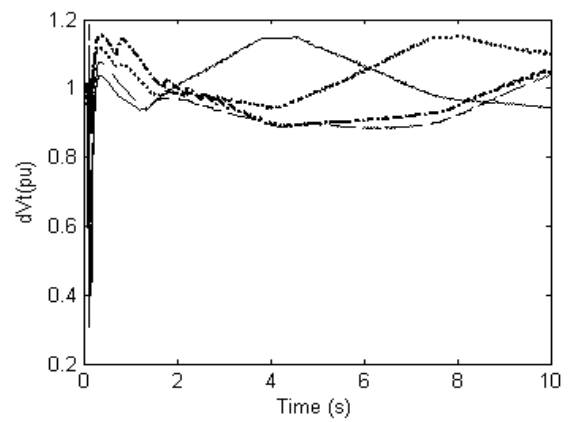

(a) Terminal voltage changes of the generators1 (dash), 2 (solid), 3 (dash-dot) and 4 (dot)

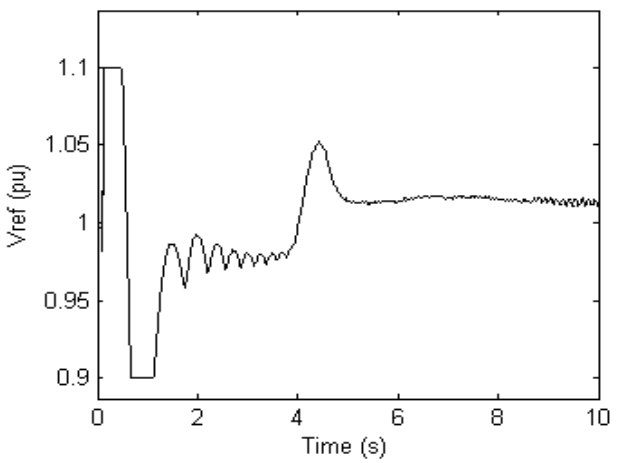

(b) Variation of STATCOM reference voltage signal under small disturbance

Fig7. The terminal voltages and Variation of STATCOM reference voltage signal 


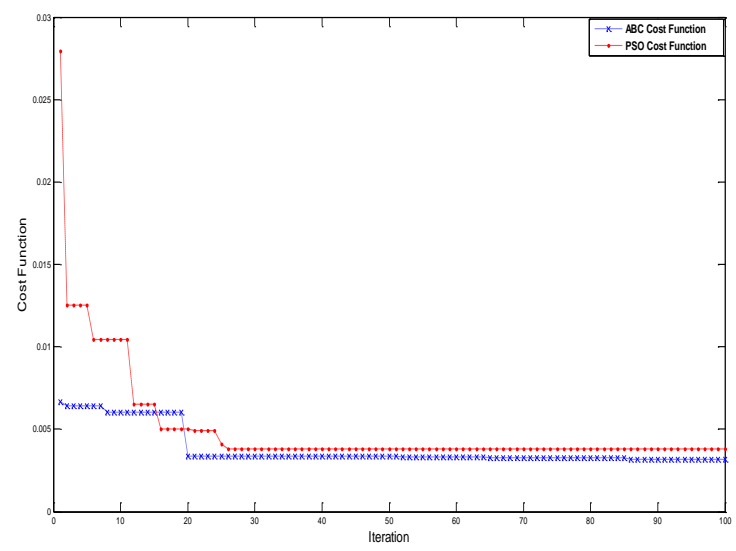

Fig8. The convergence graph of the target function $J$ relative to the number of repetitions [PSO algorithm (dash), ABC algorithm (dot)

As can be seen from the figure above, the function's convergence value using the $A B C$ algorithm reaches to the error value of 0.006 after 8 repetitions while this value is reached after 15 repetitions using the algorithm PSO, showing the higher convergence of the ABC algorithm than the PSO algorithm. On the other hand the function's convergence value after 100 repetitions in algorithm PSO reaches to a minimum of 0.004 whereas this same value in $\mathrm{ABC}$ algorithm is about 0.003 , showing the superiority of the $\mathrm{ABC}$ algorithm over the PSO algorithm in terms of the convergence accuracy. In Fig. (9-a) the electromechanical fluctuations of the local mode of the generators 3 and 4 versus time in three states of using the algorithms ABS, PSO and without using any algorithm for the adjustment of optimization parameters have been compared. This figure illustrates, damping of the local mode's electromechanical fluctuations in adjustment of the parameters is accompanied by lower fluctuations using the algorithm $\mathrm{ABC}$ than with the algorithm PSO. Also a comparison of the three states of using algorithms (ABC, PSO) and no algorithm has been made in Figs. (9-b) and (9-c) in terms of the changes of electromechanical fluctuations of the inter-area mode versus time.

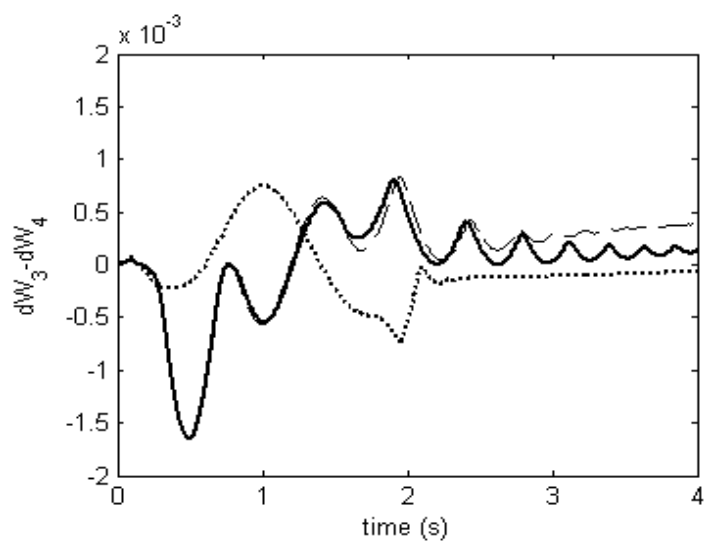

(a) Electromechanical fluctuations of the local mode of the generators 3 and 4

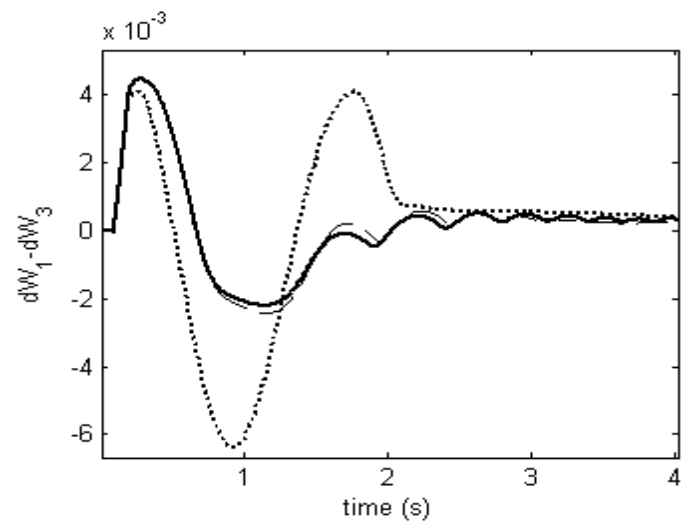

(b) Electromechanical fluctuations of the inter-area mode of the Generators 1 and 3 


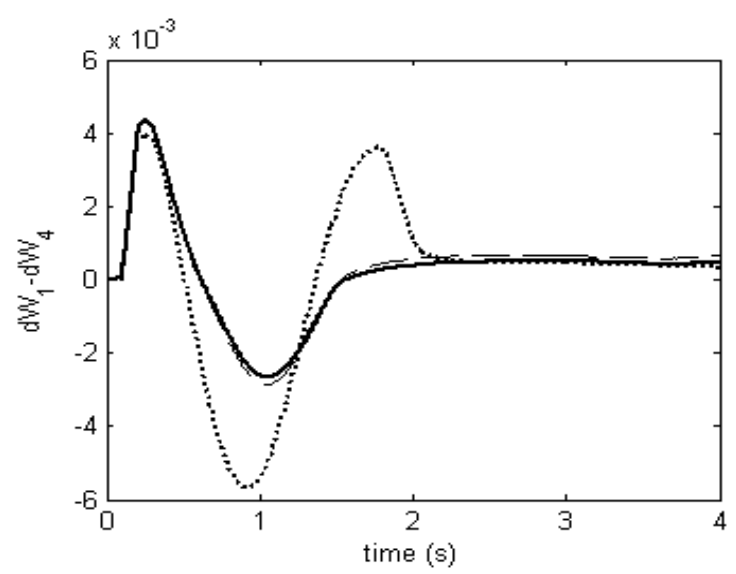

(c) Electromechanical fluctuations of the inter-area mode of the Generators 1 and 4

Fig9. Electromechanical fluctuations of the inter-area mode [PSO algorithm (dash), ABC algorithm (solid)]

These figures respectively show the better damping and lower amplitude of the inter-area electromechanical fluctuations after the 3-phase short-circuiting in generators 1-3 and 1-4. Comparing the figures above, the optimization and better adjustment of the parameters in damping of inter-area electromechanical fluctuations using $\mathrm{ABC}$ algorithm relative to the PSO algorithm is obvious. Also the voltage angle changes $(\delta)$ after the oscillation among the generators in three discussed states have been examined and compared in the Fig. (10-a).It can be observed that after the oscillation the lowest changes of the voltage angle relates to the parameter adjustment using the $\mathrm{ABC}$ algorithm. Comparison of the STATCOM reference voltage signal fluctuations under the oscillation of 3-phase short-circuit in two states of using the PSO and ABC algorithms to adjust the parameters have been represented in Fig. (10-b). Obviously as shown in this figure, the STATCOM reference voltage signal fluctuations under the oscillation of three-phase short-circuit in adjustment of the parameters using the $\mathrm{ABC}$ algorithm is lower than the PSO algorithm.

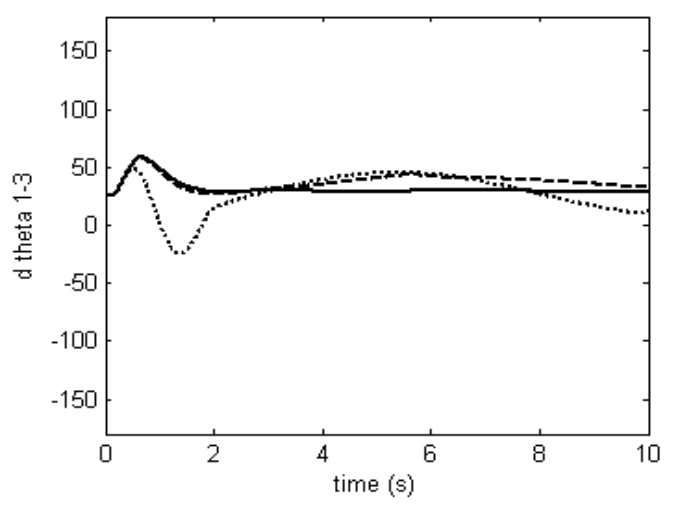

(a) The voltage angle variations $(\delta)$ generators 1 and 3

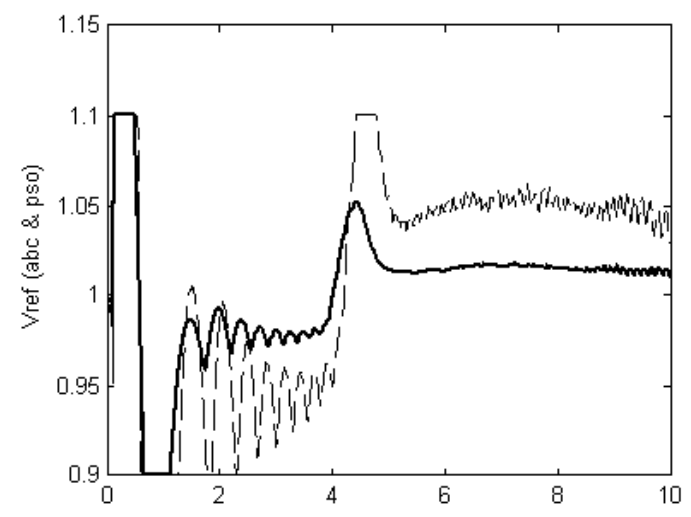

(b) Variation of STATCOM reference voltage signal under small disturbance

Fig10. Voltage angle and change of reference voltage [PSO algorithm (dash), ABC algorithm (solid)] 


\section{CONCLusion}

In this paper, for better adaption of the STATCOM and PSS parameters for better damping of the electromechanical fluctuations the $\mathrm{ABC}$ algorithm has been used. By adjusting the parameters through using the $\mathrm{ABC}$ algorithm and comparing it with the PSO algorithm and without optimization parameters, the simulation results show that the electromechanical fluctuations' damping in the regional and inter-area modes is faster compared with using PSO algorithm and more faster compared with the state not using any algorithm at all.

Also examining the voltage angle changes in simulation through the adjusted parameters using $\mathrm{ABC}$ algorithm showed that it produces the lowest voltage angle deviation compared with the other two states. In summary, the optimization after a large oscillation shows that the coordinated designing of the STATCOM and PSS controllers' parameters using the ABC algorithm considerably improves the system stability together with rapid damping of the system fluctuations as compared to the state without optimization. On the other hand, the optimization results using the $\mathrm{ABC}$ algorithm in terms of the other parameters after 3-phase short-circuit oscillation shows the superiority of the mentioned method over the PSO algorithm in adjustment of the STATCOM and PSS parameters.

APPENDIX

Generators parameters: $\mathrm{M} 1=\mathrm{M} 2=\mathrm{M} 3=\mathrm{M} 4=900 \mathrm{MVA}, \mathrm{V}=20 \mathrm{KV}, \mathrm{f}=60 \mathrm{HZ}, \mathrm{Xd}=1.305, \quad \mathrm{X}^{\prime} \mathrm{d}=0.296$, $\mathrm{X} " \mathrm{~d}=0.255, \mathrm{Xq}=0.474, \mathrm{X} " \mathrm{q}=0.243, \mathrm{X} 1=0.18$

Transformer parameters: $\mathrm{T} 1=\mathrm{T} 2=\mathrm{T} 3=\mathrm{T} 4=1000$ MVA, $\mathrm{V}=20 / 500 \mathrm{KV}, \mathrm{R} 2=0.002 \Omega, \mathrm{L} 2=0.12$, $\mathrm{Rm}=500 \Omega, \mathrm{Xm}=500 \Omega$

Transmission line parameters per $\mathrm{km}: \mathrm{R} 1=0.1755 \Omega \mathrm{R} 0=0.2758 \Omega, \mathrm{L} 1=0.8737 \mathrm{mH}, \mathrm{L} 0=3.22 \mathrm{mH}$, $\mathrm{C} 1=13.13 \mathrm{nf}, \mathrm{C} 0=8.297 \mathrm{nf}$

STATCOM parameters: V=500 KV, \pm 200 Mvar, $\mathrm{R}=0.071, \mathrm{~L}=0.22, \mathrm{~V}_{\mathrm{DC}}=40, \mathrm{C}_{\mathrm{DC}}= \pm 375 \mu \mathrm{f}, \mathrm{Vref}=1.0$ p.u, $\mathrm{Kp}=50, \mathrm{Ki}=1000$

STATCOM controller: $\Delta \mathrm{V}_{\mathrm{ST}}^{\max }=1.1 \mathrm{pu}, \mathrm{T}_{2 \mathrm{~S}}=\mathrm{T}_{4 \mathrm{~S}}=0.3 \mathrm{~s}, \mathrm{~T}_{\mathrm{WS}}=10 \mathrm{~s}, \Delta \mathrm{V}_{\mathrm{ST}}^{\min }=0.9 \mathrm{pu}$

PSSs: sensor time constant $=0.015 \mathrm{~s}, \mathrm{~V}_{\mathrm{S}}^{\min }=-0.15 \mathrm{pu}, \mathrm{V}_{\mathrm{S}}^{\max }=0.15 \mathrm{pu}$

\section{ACKNOWLEDGMENT}

The authors would like to thank the journal editor and anonymous referees for their valuable comments and suggestions which effectively improved the quality of this paper. This research work was supported by Smart Microgrid Research Center, Najafabad Branch, Islamic Azad University, Najafabad, Iran.

\section{REFERENCES}

[1] Shahgholian, G., Azimi, Z., Analysis and design of a DSTATCOM based on sliding mode control strategy for improvement of voltage sag in distribution systems, Electronics, 2016, 5(3), 41.

[2] Tavoosi, M., Fani, B., Adib, E., "Stability analysis and control of DFIG based wind turbine using FBC strategy", Journal of Intelligent Procedures in Electrical Technology, Vol. 4, No. 15, pp. 31-42, Autumn 2013 (in Persian).

[3] Shahgholian, G., Faiz, J., Fani, B., Yousefi, M.R., "Operation, modeling, control and applications of static synchronous compensator: A review", Proceeding of the IEEE/IPEC, pp. 596-601, Singapore, Oct. 2010.

[4] Ma,J.; Wang, H.J.; Lo, K.L. Clarification on power system stabiliser design. IET Gener. Transm. Distrib., 2013, 7(9), 973-981.

[5] Shahgholian, G.; Movahedi, A. Power system stabiliser and flexible alternating current transmission systems controller coordinated design using adaptive velocity update relaxation particle swarm optimisation algorithm in multi-machine power system. IET Gener. Transm. Distrib., 2016, 10(8), 1860-1868.

[6] Luburić, Z., Pandžić, H.,"FACTS devices and energy storage in unit commitment ", International Journal of Electrical Power and Energy Systems, Vol. 104, pp. 311-325, Jan. 2019.

[7] Sumathi, S.; Bansilal, N. Artificial neural network for coordinated control of STATCOM, generator excitation and tap changing transformer. International Journal of Electrical Power and Energy Systems, 2015, 64, 536-541.

[8] Khosroshahi, M.T.; Kazemi, F.M.; Jannati-Oskuee, M.R.; Najafi-Ravadanegh, S. Coordinated and uncoordinated design of LFO damping controllers with IPFC and PSS using ICA and SFLA, Journal of Central South University, 2015, 22(9), 3418-3426. 
[9] Tavana, M.R.; Khooban, M.H.; Niknam, T. Adaptive PI controller to voltage regulation in power systems: STATCOM as a case study,ISA Transactions, 2017, 66, 325-334.

[10] Xu,Y.; Tolbert,L.M.; Chiasson,J.N.; Campbell,J.B.; Peng, F.Z. A generalised instantaneous non-active power theory for STATCOM, IET Electric Power Applications, 2007, 1(6), 853-861.

[11] Velásquez, R.M.A., Lara, J.V.M., "Snubber resistor influence in the thyristor valves failure on the static VAR compensator", Engineering Failure Analysis, Vol. 89, pp. 150-178, July 2018.

[12] Ghasemi, M., Roosta, A.R., Fani, B., "Coordinated control of FACTS devices by using ADALINE neural network to enhance the transient stability of power system", Journal of Intelligent Procedures in Electrical Technology, Vol. 3, No. 9, pp. 27-40, Spring 2012 (in Persian).

[13] Shahgholian, G.; Movahedi, A.; Faiz, J. Coordinated design of TCSC and PSS controllers using VURPSO and genetic algorithms for multi-machine power system stability, International Journal of Control, Automation, and Systems, 2015, 13(2), 398-409.

[14] Kahouli, O., Jebali, M., Alshammari, B., Abdallah, H.H., "PSS design for damping low-frequency oscillations in a multi-machine power system with penetration of renewable power generations", IET Renewable Power Generation, Vol. 13,No. 1, pp. 116-127, Jan. 2019.

[15] Shahgholian, G. Development of state space model and control of the STATCOM for improvement of damping in a single-machine infinite-bus, International Review of Electrical Engineering, 2009, 4(6), 1367 1375 .

[16]Lei, X.; Li, X.; Povh, D.A. Nonlinear control for coordinating TCSC and generator excitation to enhance the transient stability of long transmission systems, Electric Power Systems Research, 2001, 59(2), 103109.

[17] Khadanga, R.K.; Satapathy, J.K. Time delay approach for PSS and SSSC based coordinated controller design using hybrid PSO-GSA algorithm, International Journal of Electrical Power and Energy Systems, 2015, 71, 262-273.

[18]Xia,S.; Chan, K.W.; Bai, X.; Guo, Z. Enhanced particle swarm optimisation applied for transient angle and voltage constrained discrete optimal power flow with flexible AC transmission system, IET Gener. Transm. Distrib., 2015, 9(1), 61-74.

[19]B.T. He, M.S. Li, T.Y. Ji, Q.H. Wu, "Optimal coordinated control of PSS and STATCOM in a multimachine power system", IEEE/APPEEC, pp. 1-6, Hong Kong, Dec. 2014.

[20] Y.L. Abdel-Magid, M.A. Abido, "Robust coordinated design of excitation and TCSC-based stabilizers using genetic algorithm", Electrical Power System Research, Vol. 69, No. 2-3pp. 129-141, May 2004.

[21]G. Shahgholian, A. Movahedi, "Coordinated design of thyristor controlled series capacitor and power system stabilizer controllers using velocity update relaxation particle swarm optimization for two-machine power system stability", Revue Roumaine Des Sciences Techniques, Vol. 59, No. 3, pp. 291-301, 2014.

[22]N.R. Sabar, M. Ayob, G. Kendall, R. Qu, "A honey-bee mating optimization algorithm for educational timetabling problems", European Journal of Operational Research, Vol. 216, No. 3, pp. 533-543, Feb. 2012.

[23] Ouyang, P., Pano, V. Comparative study of DE, PSO and GA for position domain PID controller tuning. Algorithms, 2015, 8(3), 697-711.

[24] M. Fathian, B. Amiri, A. Maroosi, "Application of honey-bee mating optimization algorithm on clustering", Applied Mathematics and Computation, Vol. 190, No. 2, pp. 1502-1513, July 2007.

[25] Shahgholian, G., Eshtehardiha, S., Mahdavinasab, H., Yousefi, M. A novel approach in automatic control based on the genetic algorithm in STATCOM for improvement power system transient stability. IEEE/ICIS, 2008, 1, 14-19, Varna.

[26]Z. Li-Ping, Y. Huan-Jun, H. Shang-Xu, "Optimal choice of parameters for particle swarm optimization", Journal of Zhejiang University- SCIENCE A, Vol. 6, No. 6, pp. 528-534, 2005.

[27] Ouyang, P., Pano, V. Comparative study of DE, PSO and GA for position domain PID controller tuning. Algorithms, 2015, 8(3), 697-711.

[28]Xiang, Y., Zhou, Y., Liu, H. An elitism based multi-objective artificial bee colony algorithm. European Journal of Operational Research, 2015, 245(1), 168-193.

[29]Chen,J.F., Do,Q.H., Hsieh, H.N. Training artificial neural networks by a hybrid PSO-CS algorithm. Algorithms, 2015, 8(2), 292-308.

[30] Hussain, A.N.,Malek, F.A.,Humayun, M.A. Rashid, M.A. Power system oscillations damping by optimal coordinated design between multiple damping stabilizers based on STATCOM device, IEEE/STUDENT, 2012, 18-23, Kuala Lumpur.

International Journal of Research Studies in Electrical and Electronics Engineering (IJRSEEE) Page | 38 
[31] Panda, S., Padhy, N.P. Optimal location and controller design of STATCOM for power system stability improvement using PSO. Journal of the Franklin Instiyue, 2008, 345, 166-181.

[32] V. Keumarsi, M. Simab, G. Shahgholian, "An integrated approach for optimal placement and tuning of power system stabilizer in multi-machine systems", International Journal of Electrical Power and Energy Systems, Vol. 63, pp. 132-139, Dec. 2014.

[33] Bhukya, J., Mahajan, V., "Mathematical modelling and stability analysis of PSS for damping LFOs of wind power system", IET Renewable Power Generation, Vol. 13,No. 1, pp. 103-115, Jan. 2019.

[34] A. Rezazadeh, M. Sedighizadeh, A. Hasaninia, "Coordination of PSS and TCSC controller using modified particle swarm optimization algorithm to improve power system dynamic performance" Journal of Zhejiang University-SCIENCE C, Vol. 11, No. 8, pp.645-653, 2010.

[35]B. Shaw, A. Banerjee, S.P. Ghoshal, V. Mukherjee, "Comparative seeker and bio-inspired fuzzy logic controllers for power system stabilizers", International Journal of Electrical Power and Energy Systems, Vol. 33, No. 10, pp. 1728-1738, Dec. 2011.

[36] T.R. Jyothsna, K. Vaisakh, "Effects of strong resonance in tuning of multiple power system stabilizers", IET Gener., Transm. Distr., Vol. 5, No. 11, pp. 1155-1164, 2011.

[37] G. Shahgholian, M. Arezoomand, H. Mahmoodian, "Analysis and simulation of the single machine infinite bus power system stabilizer and parameters variation effects", IEEE/ICIAS, pp.167-171, Kuala Lumpur, Nov. 2007.

[38] Mostafa, H.E., El-Sharkawy, M.A., Emary, A.A., Yassin, K. Design and allocation of power system stabilizers using the particle swarm optimization technique for an interconnected power system. International Journal of Electrical Power and Energy Systems, 2012, 34(1), 57-65.

[39] Shahgholian, G., Rajabi, A., Karimi, B. Analysis and design of PSS for multi-machine power systembased on sliding mode control theory. International Review of Electrical Engineering, 2010, 4(2), 2241-2250.

[40]Hong, Y.Y., Hsieh, Y.L., Interval type-II fuzzy rule-based STATCOM for voltage regulation in the power system, Energies, 2015, 8, 8908-8923.

[41] Castro, L.M., Acha, E.,Fuerte-Esquivel, C.R. A novel STATCOM model for dynamic power system simulations. IEEE Trans. on Power Systems, 2013, 28(3), 3145-3154.

[42] Shahgholian, G., Fazeli-Nejad, S., Moazzami, M., Mahdavian, M., Azadeh, M. Janghorbani, M, Farazpey, S.Power system oscillations damping by optimal coordinated design between PSS and STATCOM using PSO and ABC algorithms, IEEE/ECTICON, Chiang Mai, 2016, Thailand, 1-6.

[43] Karaboga, D., Basturk, B. A powerful and efficient algorithm for numerical function optimization: artificial bee colony (ABC) algorithm. Journal of Global Optimization, 2007, 39(3), 459-471.

[44] Karaboga,D., Ozturk, C. A novel clustering approach: Artificial Bee Colony (ABC) algorithm. Applied Soft Computing, 2011, 11(1), 652-657.

[45] Song,X., Gu, H., Tang, L., Zhao, S., Zhang, X., Li, L., Huang, J. Application of artificial bee colony algorithm on surface wave data, Computers and Geosciences, 2015, 83, 219-230.

[46] Karaboga, D., Akay, B. A comparative study of artificial bee colony algorithm. Applied Mathematics and Computation, 2009, 214(1), 108-132.

[47]Zhao, P., Yao, W., Wen, J., Jiang, L., Wang, S., Cheng, S. Improved synergetic excitation control for transient stability enhancement and voltage regulation of power systems. International Journal of Electrical Power and Energy Systems, 2015, 68, 44-51.

[48] Kundur, P."Power system stability and control, 1994, McGraw-Hill.

Citation: Ghazanfar Shahgholian, et.al. (2019). “Artificial Bee Colony Algorithm Based Approach for Power System Oscillation Damping with PSS and STATCOM”. International Journal of Research Studies in Electrical and Electronics Engineering (IJRSEEE), 5(2), pp 27-39. DOI: http://dx.doi. org/10.20431/24549436.0502004

Copyright: (c) 2019 Authors. This is an open-access article distributed under the terms of the Creative Commons Attribution License, which permits unrestricted use, distribution, and reproduction in any medium, provided the original author and source are credited. 